\title{
microRNA-21 Expression as Prognostic and Therapeutic Response Marker in Chronic Myeloid Leukaemia Patients
}

\author{
Masroor Ali Beg Mirza ${ }^{1,2}$, Sameer Ahmad Guru², Saleh Mohammed Abdullah ${ }^{3}$, \\ Aliya Rizvi ${ }^{4}$, Alpana Saxena ${ }^{3,5 *}$
}

\begin{abstract}
Background: Chronic myeloid leukaemia (CML) is a myeloproliferative disorder categorized by malignant transformation of a single stem cell of hematopoietic cells. microRNAs (miRNAs) belong to transcription regulators in hematopoiesis and their altered expression associates with pathogenesis of CML. Aim: Current study aimed to access the $m i R-21$ expression profile in CML patients and therapy response as well as its prognostic significance. Methods: $100 \mathrm{CML}$ cases, 100 controls were included in study and miR-21 expression was analyzed. Overall 9.22 mean fold increased expression was observed in CML patients before treatment. Results: Patients with different CML phases such as chronic phase, accelerated phase and blast crisis showed 7.16, 10.30 and 13.20 fold increased expression respectively. Overall 3.57 mean fold expression was observed in imatinib treated patients suggested more than 5 fold decreased expression in CML patients. Prognostic significance was calculated and observed that miR-21 expression at 7.29 fold cutoff, $75 \%$ sensitivity and $50 \%$ specificity was observed (AUC $=0.75, \mathrm{p}<0.0001$ ). Study observed $m i R-21$ overexpression in CML patients as well as gradually increased expression with advancement of disease. Conclusion: $m i R-21$ overexpression represented molecular prognostic marker and predictive tool enabling efficient monitoring of drug response and therapy outcomes in CML patients.
\end{abstract}

Keywords: Chronic myeloid- leukaemia- microRNA21- prognosis biomarker

Asian Pac J Cancer Prev, 20 (8), 2379-2383

\section{Introduction}

Chronic myeloid leukaemia (CML) is a hematological disease categorized by malignant transformation of a hematopoietic stem cells which bear the Philadelphia $(\mathrm{Ph})$ chromosome (Druker et al., 2006). Mutual chromosomal translocation $\mathrm{t}(9 ; 22)(\mathrm{q} 34 ; \mathrm{q} 11)$ among the long arms of chromosome number 9 and 22. This rearrangement results in the abnormal hybrid BCR-ABL elongated 8 $\mathrm{kb}$ ribonucleic acid (RNA) fragment and its product constitutively activated tyrosine kinase and implicated in CML (Mineo et al., 2012). Imatinib mesylate (IM) is a specific tyrosine kinase inhibitor in CML patients is the standard first line therapy for CML patients. However, main imatinib resistance and molecular evidence of persisting disease was observed in 20-25\% imatinib treated patients (Bhutra et al., 2014).

miRNAs are often originate from polycistronic clusters containing an average of 23 miRNAs. These polycistronic clusters are typically located in fragile regions prone to deletions and other molecular harmful alterations (Venturini et al., 2007). miRNAs control many cellular pathways responsible for apoptosis, cell proliferation and tumorigenesis based on target sequences( Bhattacharyya ei al 2006; Carthew et al., 2002 ). Thus, gene regulation and role of several miRNAs are presently under study in several human diseases and synthetic compounds that regulate miRNAs, are especially imperative for innovative treatment way in CML (Calin et al., 2004). MiR-21 was the primary miRNAs observed in the human genome and is frequently up-regulated in cancer having the majority of its reported targets as tumor suppressors. It has been involved in promoting tumor growth, cell proliferation, inflammation and angiogenesis. In particular, $m i R-21$ is strongly involved in apoptosis regulation, being known to evade cell death (Feng et al., 2010). Studies have shown that $m i R-21$ was upregulated in different types of malignancy and contributes to chemotherapy resistance. One of those studies by Bai et al., (2011) demonstrates that resistance of the hemotherapeutic agent Daunorubicin (DNR) in K562 cell leukemic line is related to up-regulation of $m i R-21$ expression. Thus the study aimed to evaluate the role of $m i R-21$ expression and their association with therapy and symptoms of CML patients.

${ }^{1}$ Department of Toxicology, Jamia Hamdard University, ${ }^{2}$ Department of Biochemistry, Maulana Azad Medical College, ${ }^{5}$ Department of Biochemistry, MAMC, New Delhi, ${ }^{4}$ Department of Pathology, King George Medical University, Lucknow, India, ${ }^{3}$ Department of Medical Laboratory, Faculty of Applied Medical Sciences, Jazan University, KSA. *For Correspondence: biochempublications@gmail.com. Masroor Ali Beg Mirza and Sameer Ahmad Guru have equal contribution in this study. 


\section{Materials and Methods}

Peripharal blood sample collection and total RNA extraction

Present study included 100 clinically confirmed by the diagnosis confirmed by presence of Bcr/Abl transcript for Chronic Myeloid Leukemia patients, and 100 healthy control subjects. $3 \mathrm{ml}$ of peripharal blood sample were collected in EDTA vials from all patients before and after treatment of Imatinib as well as from healthy subjects. After blood sample collection, total RNA extraction was done by Trizol $^{\circledR}$ reagent (Thermo Scientific, USA), after extracted total RNA sample were stored in DEPC treated tubes at $-80^{\circ} \mathrm{C}$. The purity and integrity of the total RNA were accessed by the A260/280 ratio using nanospectrophotometer. Study was performed at Maulana Azad Medical College, New Delhi and approved by Institutional Ethics Committee.

\section{Polyadenylation of total RNA}

The Polyadenylation was done using enzyme Poly-A Polymerase and rATP (Agilent) in 0.5-ml tubes. Nuclease free $\mathrm{H}_{2} \mathrm{O}$ was added to reach volume upto $20 \mu \mathrm{l}, 4.0$ micro litters of $5 \mathrm{X}$ poly A buffer solution 1 micro litters of rATP $(10 \mathrm{mM})$ and $100 \mathrm{ng}$ of extracted total RNA. The reaction was kept at $37^{\circ} \mathrm{C}$ for 35 minutes and then reactions were at incubated $95^{\circ} \mathrm{C}$ to terminate adenylation for 5 minutes. Tubes were immediately transferred to ice and reaction tubes were kept on $-80^{\circ} \mathrm{C}$ for next $m i R-21$ expression study.

\section{Complementary DNA synthesis and qRT-PCR}

Complementary DNA synthesis was performed using reverse transcriptase enzyme and other essential reagents, subsequently added to make the poly (A)-tailed microRNAs into cDNA using an oligo-dT nucleotide sequences (adapter primer) supplied with the kit (Agilent, Cat\#600036) . microRNA-21 expression was analysed by quantitative real-time PCR method using SYBR Green qPCR mastermix. snU6 was used as housekeeping and microRNA- 21 specific forward and a common universal reverse primer was used for expression study using cDNA as template. Reaction programmed as activation of polymerase at $95^{\circ} \mathrm{C}$ for 5 minutes, followed by 40 cycles. denaturation at $95^{\circ} \mathrm{C}$ for 30 seconds, annealing at $60^{\circ} \mathrm{C}$ for 30 seconds, and extension at $72^{\circ} \mathrm{C}$ for 30 seconds. Melting curve investigation was performed to make sure the desired amplification of microRNA-21.

\section{Statistical analysis}

All the data analysis was done using SPSS version 20.0 and Graph Pad Prism software version 6.05 for window. Parametric, nonparametric and paired sample test were used to analyse the data on the basis of observation among the different groups. Ct values were obtained from all the reaction performed by qRT-PCR, each sample examined in triplicate. Expression pattern was recorded by using $2^{-(\Delta \Delta C t)}$ calculation method for MicroRNA expression. Results more than or less than 1 were taken as reference to indicate upregulation or low regulation of expression, respectively. $p$ value was less than 0.05 was measured to be statistically significant.

\section{Results}

Demographic and clinical features of CML cases and Healthy controls subjects: Total number of 100 cases and control subjects were included in study and all the clinical and demographic characteristic were depicted in Table 1.

\section{MicroRNA-21 expression in CML patients before treatment}

It has been observed that overall $m i R-21$ expression in patients was 9.22 fold increased compared to control. Significant difference $(\mathrm{p}<0.0001)$ was observed in $m i R-21$ expression among patients with different stages such as chronic phase (7.16 fold), accelerated phase (10.30 fold) and blast crisis (13.20 fold). However, no significant disparity was recorded among gender (male and females) and different age groups (Table 2).

\section{Effect of Imatinib treatment on MicroRNA-21 expression} in CML patients

All the patients were treated for 6 months and then

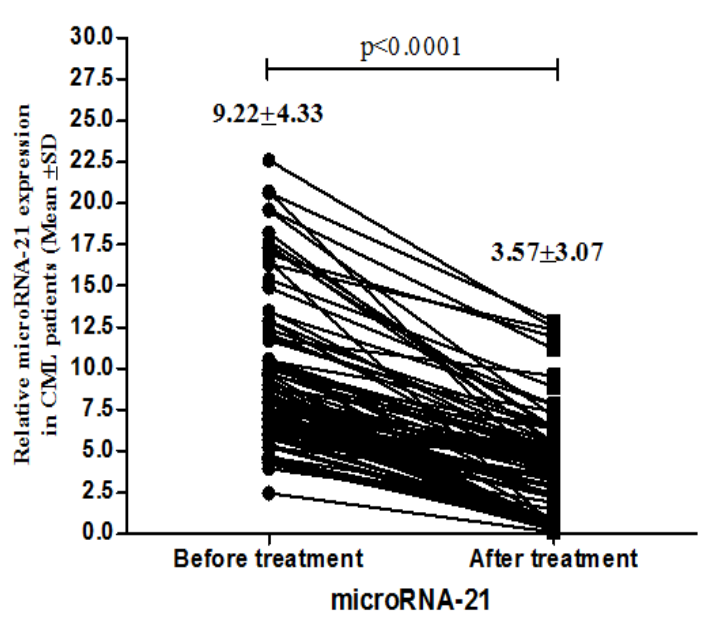

Figure 1. microRNA-21 Expression before and after Treatment of Imatinib

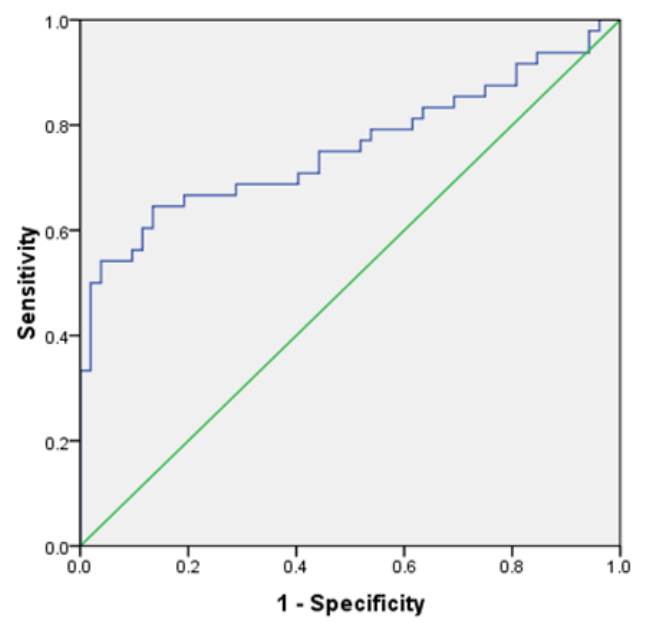

Figure 2. ROC Curve for microRNA-21 Expression among Chronic Phase vs Accelerated, Blast Crisis Phase of CML Patients 
Table 1. Demographic and Clinical Features of CML Cases and Healthy Control Subjects

\begin{tabular}{lcc}
\hline Variables & $\begin{array}{c}\text { CML cases } \\
\mathrm{n}(\%)\end{array}$ & $\begin{array}{c}\text { Healthy controls } \\
\mathrm{n}(\%)\end{array}$ \\
\hline Total & $100(100 \%)$ & $100(100 \%)$ \\
Gender & $73(73 \%)$ & $70(70 \%)$ \\
$\quad$ Males & $27(27 \%)$ & $30(30 \%)$ \\
$\quad$ Females & & \\
Age (In years) & $57(57 \%)$ & $60(60 \%)$ \\
$\quad<45$ & $43(43 \%)$ & $40(40 \%)$ \\
$>45$ & & \\
CML stages & $52(52 \%)$ & \\
Chronic Phase & $29(29 \%)$ & \\
Accelerated Phase & $19(19 \%)$ & \\
$\quad$ Blast crisis & & \\
Thrombocytopenia & $59(59 \%)$ & \\
$\quad$ Yes & $41(41 \%)$ & \\
No & & \\
Molecular response & $59(59 \%)$ & \\
MMR & $41(41 \%)$ & \\
No MR & & \\
Haematological response & & \\
MHR & $48(48 \%)$ & \\
Minor HR & $15(15 \%)$ & \\
Loss HR & $37(37 \%)$ & \\
\hline
\end{tabular}

blood sample were collected for $m i R-21$ expression analysis to compare with before treatment and found to be significant reduction in $m i R-21$ expression showed in figure 1. Patients had 9.22 mean fold increased expression before treatment of imatinib and after treatment it became 3.57 mean fold expression $(\mathrm{p}<0.0001)$. After treatment, $m i R-21$ expression was compared in different groups of molecular and haematological responses but no statistical significant relationship was recorded in $m i R-21$ expression (Table 3).

Table 2. microrna-21 Expression before Treatment among Different Variables Group

\begin{tabular}{lcc}
\hline Variables & Mean + SD & p value \\
\hline Over all miR-21 expression & $9.22+4.33$ & - \\
Gender & & \\
$\quad$ Males & $8.26+3.46$ & 0.39 \\
$\quad$ Females & $9.57+4.58$ & \\
Age (In years) & & \\
$\quad<45$ & $9.21+4.17$ & 0.78 \\
$\quad>45$ & $9.23+4.58$ & \\
CML stages & & \\
$\quad$ Chronic Phase & $7.16+1.95$ & $<0.0001$ \\
$\quad$ Accelerated Phase & $10.30+4.14$ & \\
$\quad$ Blast crisis & $13.20+5.59$ & \\
\hline
\end{tabular}

Table 3. microrna-21 Expression Profile after Treatment among Different Groups

\begin{tabular}{lcc}
\hline Variables after treatment & Mean + SD & $p$-value \\
\hline Thrombocytopenia & & \\
$\quad$ Yes & $3.65+3.02$ & 0.58 \\
$\quad$ No & $3.47+3.17$ & \\
Molecular response & & \\
MMR & $3.95+3.34$ & 0.23 \\
No MR & $3.03+2.57$ & \\
Haematological response & & \\
$\quad$ MHR & $3.42+2.89$ & 0.61 \\
$\quad$ Minor HR & $3.24+3.18$ & \\
$\quad$ Loss HR & $3.91+3.29$ & \\
\hline
\end{tabular}

Table 4. Therapeutic Response in mir-21 Expression Reduction of Different CML Phases

\begin{tabular}{lccc}
\hline Variables & $\begin{array}{c}\text { Before } \\
\text { treatment }\end{array}$ & $\begin{array}{c}\text { After } \\
\text { treatment }\end{array}$ & p value \\
\hline CML Phase & & & \\
Chronic Phase & $7.16+1.95$ & $2.65+1.99$ & $<0.0001$ \\
Accelerated Phase & $10.30+4.41$ & $3.94+3.12$ & $<0.0001$ \\
Blast crisis & $13.20+5.59$ & $5.55+4.31$ & $<0.0001$ \\
\hline
\end{tabular}

MicroRNA-21 expression and therapy response in CML patients with respect to phases

$m i R-21$ expression was compared before and after therapy in different phases of patients and found significant reduction in miR-21 expression. Patients in chronic phase before therapy had 7.16 fold expression and after treatment 2.65 fold expression observed and the differences was obtained to be significant $(\mathrm{p}<0.0001)$. Patients before treatment in accelerated, blast crisis had $10.30,13.20$ fold $m i R-21$ expression however, after treatment it reduced to 3.94, 5.55 fold expression respectively and the differences in reduction was found to be significant $(\mathrm{p}<0.0001)$ (Table 4).

Prognostic Significance of microRNA-21 in CML patients

To examine the function of $m i R-21$ as predictive/ prognostic biomarker for CML patients, phases were categorised into two groups and ROC curves analysis. ROC curve were plotted between chronic phase vs accelerated, blast crisis phase of CML patients. ROC curves with respect to chronic vs accelerated and blast crisis phase of CML at best possible cut-off value of 7.29 fold increases in $m i R-21$ expression, sensitivity and specificity were $75 \%$ and $50 \%$ respectively (AUC $=0.75$, $\mathrm{p}<0.0001$ ) (Figure 2, Table 5).

Table 5. ROC Curve for microRNA-21 Prognostic Efficacy

\begin{tabular}{lccccc}
\hline $\begin{array}{l}\text { AUC } \\
(95 \% \mathrm{CI})\end{array}$ & $\begin{array}{c}\text { Standard } \\
\text { error }\end{array}$ & Sensitivity & Specificity & $\begin{array}{c}\text { Cutoff } \\
\text { value } \\
\text { (Fold } \\
\text { change) }\end{array}$ & p value \\
\hline 0.75 & 0.05 & $75 \%$ & $50 \%$ & 7.29 & $<0.0001$ \\
\hline
\end{tabular}




\section{Discussion}

Chronic Myeloid Leukaemia (CML) recognised as blood malignancy regarded by the neoplasic alteration of hematopoietic stem cells and interferon- $\alpha$ was the first effective therapy for CML treatment. This agent was the only choice for CML patients treatment, until the new therapeutic approach arrived such as tyrosine kinase inhibitor, Imatinib (Frazer et al., 2007). Although, in recent years new tyrosine - kinase inhibitors (TKIs) have been emerged and allogenic stem cell transplantation is the merely curative treatment for CML (Hehlmann et al., 2007).

Present study evaluated the $m i R-21$ expression in CML patients and impact of imatinib therapy on miR-21 expression. It was observed that 9.22 mean fold increased expression was observed in CML patients before treatment of imatinib. Before treatment of the patients, CML phases had significant differences in $m i R-21$ expression among chronic phase, accelerated and blast crisis had more than 3 and 5 fold increased expression in $m i R-21$ expression compared to chronic phase.

$m i R-21$ has been found to be increased in hematological malignancies (Volinia et al., 2006) and several studies have suggested microRNAs involved in pathogenesis of malignant transformation and advancement of disease. Chan et al., (2005) strongly suggested that $m i R-21$ have been one of the very important candidate involved in oncogenic activity. It was suggested that knockout of microRNA-21 triggered caspases activation and led to enhanced apoptosis and causes cell death in cultured glioblastoma cell line, suggesting that $m i R-21$ upregulation could be a against of apoptosis (Chan et al., 2005).

Patients who were treated for 6 months with imatinib showed significantly more than 5 fold reduction in $m i R-21$ expression. Patients in chronic phase showed more than 4 fold reduction in $m i R-21$ expression after therapy. Patients in accelerated and blast crisis phase had more than 6 and 7 fold down regulation of $m i R-21$ expression after treatment of imatinib.

Prognostic efficacy of $m i R-21$ was analysed and it was observed that microRNA-21 could be used as prognostic indicator for patients' different stage monitoring, at 7.29 fold of cutoff value can be used to predict the stages of CML patients and at this level sensitivity was $75 \%$ observed at 0.75 AUC. Patients with more than 7.29 fold could be indicative of disease progression and microRNA-21 expression could be used as therapy response marker as we observed after treatment in reduction of $m i R-21$ expression.

A study by Chen et al., (2014), showed that up-regulation of $m i R-21$ expression was found in the blood serum, linked with activated B-cell lymphoma and associated with initial-stage disease. Jones et al., (2014) reported that cell free microRNA-21 was over expressed in patients with classic Hodgkin lymphoma and could be used as therapy response marker.

$m i R-21$ was seen to be noticeably upregulated in patients with chronic lymphocytic leukemia (Fulci et al., 2007) and $m i R-21$ expression levels were notably elevated in chronic lymphocytic leukemia patients was associated with bad prognosis of disease (Rossi et al., 2010). Riccioni et al., (2014) found that myeloid blasts of patients with leukemia had up-regulated microRNA-21.

It was observed that expression changes in microRNAs associated with imatinib resistance (Flamant et al., 2010) and $m i R-21$ up-regulation induces Daunorubicin resistance in the K562 cell line by regulating the expression of PTEN. Bai et al., (2011) revealed that $m i R-21$ overexpression leads down regulation of PTEN activity and thereby increases the AKT action. Several other studies also showed that microRNA-21 overexpression contributes to treatment resistance in breast cancer (Gong et al., 2011), ovarian cancer (Echevarría-Vargas et al., 2014) and other neoplasias (Pan et al., 2010). It has also found that low expression of microRNA-21 has shown to be increased in chemotherapeutic outcome of taxol based drug in breast carcinoma cells (Mei et al., 2010).

In conclusion, present study revealed that the increased microRNA-21 expression was associated with different stages of CML patients and microRNA-21 overexpression represent molecular prognostic marker and predictive tool enabling efficient monitoring of drug response and therapy outcomes in CML patients.

\section{Acknowledgments}

Authors thank to all the study participants.

\section{Funding}

No funding support received.

\section{Ethics approval and consent to participate} Yes.

\section{Conflicts of interest}

None.

\section{References}

Bai H, Xu R, Cao Z, et al (2011). Involvement of miR-21 in resistance to daunorubicin by regulating PTEN expression in the leukaemia K562 cell line. FEBS Lett, 585, 402-8.

Bhattacharyya SN, Habermacher R, Martine U, et al (2006). relief of microRNA-mediated translational repression in human cells subjected to stress. Cell, 125, 1111-24.

Bhutra S, Lenkala D, LaCroix B, et al (2014). Identifying and validating a combined mRNA and MicroRNA signature in response to imatinib treatment in a chronic myeloid leukemia cell line. PLoS One, 9, e115003.

Calin GA, Liu C-G, Sevignani C, et al (2004). MicroRNA profiling reveals distinct signatures in B cell chronic lymphocytic leukemias. Proc Natl Acad Sci U S A, 101, 11755-60.

Carthew RW (2002). RNA interference: the fragile X syndrome connection. Curr Biol, 12, R852-4.

Chan JA, Krichevsky AM, Kosik KS (2005). MicroRNA-21 is an antiapoptotic factor in human glioblastoma cells. Cancer Res, 65, 6029-33.

Chen W, Wang H, Chen H, et al (2014). Clinical significance and detection of microRNA-21 in serum of patients with diffuse large B-cell lymphoma in Chinese population. Eur J Haematol, 92, 407-12. 
Druker BJ, Guilhot F, O'Brien SG, et al (2006). Five-year follow-up of patients receiving imatinib for chronic myeloid leukemia. N Engl J Med, 355, 2408-17.

Echevarría-Vargas IM, Valiyeva F, Vivas-Mejía PE (2014). Upregulation of $m i R-21$ in cisplatin resistant ovarian cancer via JNK-1/c-Jun pathway. PLoS One, 9, e116447.

Frazer R, Irvine AE, McMullin MF (2007). Chronic myeloid leukaemia in the 21 st century. Ulster Med J, 76, 8-17.

Feng Y, Chen X, Gao L (2010). Knockdown of miR-21 as a Novel Approach for Leukemia Therapy. J Formos Med Assoc, 109, 621-3.

Flamant S, Ritchie W, Guilhot J, et al (2010). Micro-RNA response to imatinib mesylate in patients with chronic myeloid leukemia. Haematologica, 95, 1325-33.

Fulci V, Chiaretti S, Goldoni M, et al (2007). Quantitative technologies establish a novel microRNA profile of chronic lymphocytic leukemia. Blood, 109, 4944-51.

Gong C, Yao Y, Wang Y, et al (2011). Up-regulation of $m i R$-21 mediates resistance to trastuzumab therapy for breast cancer. J Biol Chem, 286, 19127-37.

Hehlmann R, Hochhaus A, Baccarani M (2007). Chronic myeloid leukaemia. Lancet, 370, 342-50.

Jones K, Nourse JP, Keane C, et al (2014). Plasma microRNA are disease response biomarkers in classical hodgkin lymphoma. Clin Cancer Res, 20, 253-64.

Mei M, Ren Y, Zhou X, et al (2010). Downregulation of $m i R$ 21 enhances chemotherapeutic effect of taxol in breast carcinoma cells. Technol Cancer Res Treat, 9, 77-86.

Mineo M, Garfield SH, Taverna S, et al (2012). Exosomes released by K562 chronic myeloid leukemia cells promote angiogenesis in a src-dependent fashion. Angiogenesis, 15, $33-45$.

Pan X, Wang Z-X, Wang R (2010). MicroRNA-21: A novel therapeutic target in human cancer. Cancer Biol Ther, 10, 1224-32.

Rossi S, Shimizu M, Barbarotto E, et al (2010). MicroRNA fingerprinting of CLL patients with chromosome $17 \mathrm{p}$ deletion identify a miR-21 score that stratifies early survival. Blood, 116, 945-52.

Riccioni R, Lulli V, Castelli G, et al (2015). MiR-21 is overexpressed in NPM1-mutant acute myeloid leukemias. Leuk Res, 39, 221-8.

Venturini L, Battmer K, Castoldi M, et al (2007). Expression of the miR-17-92 polycistron in chronic myeloid leukemia (CML) CD34+ cells. Blood, 109, 4399-405.

Volinia S, Calin GA, Liu CG, et al (2006). A microRNA expression signature of human solid tumors defines cancer gene targets. Proc Natl Acad Sci U S A, 103, 2257-61.

\section{(ब) $(1)$}

This work is licensed under a Creative Commons AttributionNon Commercial 4.0 International License. 